\title{
Performance of hydrophobized historic solid masonry - Experimental approach
}

Hansen, T.K.; Bjarløv, Søren Peter; Peuhkuri, Ruut Hannele; Hansen, K.K.

Published in:

Construction and Building Materials

Link to article, DOI:

10.1016/j.conbuildmat.2018.08.145

Publication date:

2018

Document Version

Peer reviewed version

Link back to DTU Orbit

Citation (APA):

Hansen, T. K., Bjarløv, S. P., Peuhkuri, R. H., \& Hansen, K. K. (2018). Performance of hydrophobized historic solid masonry - Experimental approach. Construction and Building Materials, 188, 695-708.

https://doi.org/10.1016/j.conbuildmat.2018.08.145

\section{General rights}

Copyright and moral rights for the publications made accessible in the public portal are retained by the authors and/or other copyright owners and it is a condition of accessing publications that users recognise and abide by the legal requirements associated with these rights.

- Users may download and print one copy of any publication from the public portal for the purpose of private study or research.

- You may not further distribute the material or use it for any profit-making activity or commercial gain

- You may freely distribute the URL identifying the publication in the public portal 


\section{Performance of hydrophobized historic}

\section{2 solid masonry - experimental approach}

T. K. Hansen ${ }^{a^{*}}$, S.P. Bjarløv ${ }^{a}$, R. H. Peuhkurib , K. K. Hansen ${ }^{a}$

${ }^{\text {a }}$ DTU Civil Engineering, Technical University of Denmark, Kgs. Lyngby, Denmark

${ }^{\mathrm{b}} \mathrm{SBi}$, Danish Building Research Institute, Aalborg University Copenhagen, Denmark

*Corresponding author:tekhan@byg.dtu.dk DTU Civil Engineering, Brovej 118, DK-2800 Kgs. Lyngby, Denmark

\section{Abstract}

The hygrothermal conditions in historic solid masonry are expected to change for the worse, with the application of internal insulation. Nevertheless, internal insulation plays a role in a holistic energy retrofit of historic buildings. With careful considerations and correct application, hydrophobic treatment may help remedy moisture ingress from external rain loads. This study includes experimental investigations of the effect on hygrothermal performance of various hydrophobization treatments on both brick and air lime mortar. An investigation of water migration through masonry applied with imitated climatic loads is also reported. The study showed a larger efficiency of hydrophobization on specimens of brick compared to the efficiency of hydrophobization of specimens of air lime mortar, which may be problematic in cases where mortar joints are the primary means for water ingress. Silane-based treatments generally proved to be most efficient in brick, whereas a variety of other active components were most successful in air lime mortar treatment. The investigation of water migration showed a distinct effect of silane, cream hydrophobization, though most evident in the external part of the brick.

\section{Keywords}

Hydrophobization, historic masonry, internal insulation, surface treatment, ceramic brick, air lime mortar 


\section{Introduction}

Reducing the energy consumption in the existing building stock is a vital measure in the goal of global reduction of energy consumption. In Europe, the energy consumption from the building sector constitutes $40 \%$ of the overall energy consumption [1], yielding a large potential for improvements in the field. The improvements should not be limited to new, sustainable constructions, but can also be attributed historical buildings by means of energy efficient renovations. In Denmark, $60 \%$ of the existing building stock of multistory residential buildings were constructed prior to 1950 [2], often yielding preservation worthy façades as the aesthetic expression presents cultural, local and traditional importance. This excludes the possibility of external insulation.

Internal insulation is therefore often the only way to reduce heat loss through the external walls in historic buildings. In addition to the reduction in energy consumption, an advantage of reducing heat loss through façades is the improved thermal comfort, as the surface temperature of the interior wall increases. However, the application of internal insulation to an old façade will dramatically change the hygrothermal conditions of the wall, as the temperature and drying potential is reduced, yielding the possibility for interstitial condensation [3]. The hygrothermal conditions in the construction can reach undesirable states due to both internal (vapour) and external (vapour and liquid) moisture loads, and there are several risks associated with the undesirable moisture conditions, e.g. mould growth, frost damage, decay of embedded wood, and general degeneration of the construction. External moisture loads appear in the form of vapour/humidity and wind-driven rain (WDR). WDR is a significant parameter in regards to the hygrothermal performance of external facades [4][5]. When it comes to internally insulated masonry walls, WDR has also proven to be a negative contributor to the hygrothermal performance [6]. Finken et al. state that WDR can be the most critical factor in regards to moisture in a façade of porous building materials, as opposed to interstitial condensation, reduced drying capability and temperature when internal insulation is applied [5]. Through hygrothermal simulations and measurements, Künzel et al. found that an estimated $70 \%$ of WDR is absorbed by means of capillary action [7]. This observation was based on a one-dimensional validation of measured water content in three cases of different porous building materials installed in a western wall, and thus susceptible to exterior climate. Odgaard et al. found that hydrophobization had a positive effect on internally insulated walls during summer, however it impeded evaporation of interstitial condensation during winter periods [8]. 
Hydrophobization treatments may prevent, or at least reduce, penetration of liquid water from external conditions. Thus it may have a positive effect on the moisture conditions within a wall, and impede moisture accumulation due to rain penetration. Therefore, a hydrophobization treatment may enhance the service life of an internally insulated wall, as the risk of moisture related damages such as frost damage, cracking, wood degradation and mould is also reduced. An old-fashioned method for hydrophobization is found in old surface treatments, such as façade painting. However, this is not desired for listed or culturally valued buildings, as it changes the architectural expression. A previous study of internal insulation applied to external walls showed a case with a painted façade yielding excellent results in regards to hygrothermal conditions at critical points [9]. This success may be attributed to the paint serving as a water repellent; however the façade was also northbound and only a thin layer of insulation was applied.

Furthermore, both hygrothermal simulation [5] and experimental [10] studies have shown a reduction in heat loss through impregnated external walls, due to the reduced thermal conductivity caused by the dryer state of the wall. In addition, moisture within the insulation material compromises the efficiency [5][3]. There is a large variety of hydrophobic treatments available on the market, however they may not have the same efficiency with use on various materials, and when studying historic masonry holistically, the efficiency on both brick and lime mortar must be taken into consideration.

Many hydrophobic agents are based on silicone in the form of either silane or siloxane, or even a hybrid of both [11]. Both active compounds react with silicates in the building material and create $\mathrm{CH}_{3}$-molecules which are hydrophobic, like the other non-polar carbonaceous groups $\mathrm{CH}$ and $\mathrm{CH}_{2}$. Lime does not contain silicates in itself, however sand grains as aggregates in lime mortar do. Therefore the silicone based hydrophobic treatments may not bind as well to lime mortar as they do not bind to the binding agent itself as they do on e.g. cement or brick.

The main difference between the silane and the siloxane based agents is that the silane molecules have a smaller structure and lower viscosity, and thus the ability for deeper penetration into porous materials. Silane is also more volatile, and thus higher concentrations are used for achieving good results [12]. Siloxane is a more complex compound and thus larger molecules, decreasing the penetration depth, leaving the porous material more vulnerable if the external surface is damaged. Siloxane is less volatile, and lower concentrations can be used, with good results in regards to repelling water. In some cases, nanotechnology has been implemented in an attempt to improve the efficiency of hydrophobization agents. 
Recent research includes investigations of the effect of external moisture loads on the hygrothermal performance of internally insulated walls, and the prevention or reduction of external water penetration, e.g. from wind driven rain. Solar radiation can be a positive contributor to a wet façade by means of increased drying and reduced condensation potential, but it can also drive the moisture further into the construction [13].

The following studies in the field of hydrophobization relate to the present study. A study by Guizzardi et al. from 2015 of masonry walls with severe wetting [21] yielded information about migration of external water loads through masonry. The experiment revealed that interfaces posed as hydraulic resistances/barriers, and that the moisture transport occurred faster in the fine pored bricks than in mortar joints. In contrast, van Hees found that the mortar joints were the weakest part of hydrophobized masonry [22]. He observed a difference in the efficiency of hydrophobization treatments on brick and mortar, yielding mortar joints a possible way for water ingress, Zhang et al. have investigated the efficiency of silane water repellent impregnation on cement based mortars and concrete [10], and found that the capillary suction was significantly reduced. Slap $\varnothing$ et al. have found, that fresh mortars with high water content improved masonry's resistance to WDR, as the mortar-brick interface becomes less porous [22]. Engel et al. [22] performed a study on water absorption, drying and vapour diffusion of hydrophobized brick specimens. They examined 5 silane based creams of different concentrations, and two fluid hybrid agents. They found significant water absorption reduction, and with no influence on the vapour diffusion resistance. Their drying experiment showed that specimens hydrophobized with agents of lesser concentration of active ingredients, dried faster, thus an impregnation should be applied with the lowest, effective concentration. An older study from 1995 by Charola [12] found a reduction of 5-10\% in water vapour permeability with silicon-based hydrophobization treatments. Couto et al. [23], who investigated silicone-based water-repellents on ceramic brick, also found a reduction in vapour permeability of hydrophobized brick specimens in some water-repellent treatments. Van Hees [24] found a limited effect of hydrophobization on vapour diffusion however, he found the hydrophobization treatments to have a high impact on the drying process, as also found by Couto et al. [23] for most investigated treatments. Lubelli et al. [25] tested the efficiency of two nano-coatings on bricks, and found significantly reduced water absorption, and little effect on the drying, however, the penetration depth was found to be much lower than traditional products. Finken et al. found, through a study of hydrophobization based on several hygrothermal simulations, that hydrophobization has a positive impact on the hygrothermal conditions within an internally insulated façade. In the simulation, the entire wall became 
dryer, compared to unhydrophobized cases [5]. Finally, Slapø et al. performed a similar large scale study on masonry panels however, the water loads were provided with high pressure for 5 hours. They found the tested water repellents to be ineffective to high pressure driving rain after a few minutes of water loads; this inefficiency was attributed the extreme testing conditions.

This investigation focuses on the efficiency and effect of various hydrophobization agents on historic masonry from a holistic point of view. Initially a screening of 16 different hydrophobization agents is performed. The initial investigation includes experiments on brick and lime mortar in regards to penetration depth of hydrophobization agent, water absorption, and drying. Furthermore, the effect of hydrophobization on vapour diffusion is examined as well as a large scale experiment involving monitoring of the migration of water through masonry wall sections and the recorded effects of hydrophobization.

\section{Method}

As stated in the introduction, this study includes 3 laboratory experiments performed on historic brick, and air lime mortar with properties resembling historic masonry. These parts consist of;

1) Initial investigation: 16 different hydrophobization agents (silane, siloxane, hybrids, and nanotechnology) were applied to specimens of ceramic brick and air lime mortar. The performance of each agent was evaluated based on penetration depth, water absorption and drying

2) Influence on vapour diffusion: 3 hydrophobization agents (N, J, P) were applied to specimens of ceramic brick and air lime mortar to determine a possible effect on vapour diffusion properties

3) Water migration through masonry: The effect of a creamy, silane based hydrophobization agent (J) on masonry was investigated by monitoring water migration

The initial investigation was performed to get an overview of the efficiency and differences between the various types of agents. Steps 2 and 3 of the investigation were partially based on results from the initial investigation, and partially chosen to test a variety of types of hydrophobization agents. For part 2, the chosen agents included N, a silane based liquid agent, J, a silane based creamy agent, and $\mathrm{P}$, a hybrid agent that is a 2-component agent diluted in an organic solvent. For the $3^{\text {rd }}$ investigation, hydrophobization on entire masonry sections, the creamy agent J was used again. The 
cream based agent, J, used in steps 2) and 3) was chosen because it had shown good properties in regards to hydrophobization of brick, and medium performance with air lime mortar. N and P both showed a good efficiency in brick specimens; however $\mathrm{P}$ showed good performance in lime mortar, whereas $\mathrm{N}$ did not perform well.

The three studies were conducted in collaboration in order to study the effects of various hydrophobization agents on the hygrothermal behavior of historic masonry components individually, as well as investigating the combined effects of hydrophobization on masonry. By initially investigating a variety of types of agents from various manufacturers, the field could be reduced for the investigation of the influence on vapour permeability, and more specimens of each type could be included. For the investigation of water migration through masonry, only one hydrophobization treatment was used. This agent was chosen prior to the initial tests performed, however it was chosen due to some preliminary experimentation with the product.

\subsection{Materials}

As the study refers to historic masonry, the experiments have been carried out on specimens of brick and lime mortar. Both the brick and mortar included in the study, were chosen to imitate historic building materials, and are also the materials used in larger scale studies of historic masonry at the Technical University of Denmark [8]. The bricks were all yellow soft-molded bricks from Helligs $\varnothing$ Teglværk in Denmark, with a dry density of approximately $1677 \mathrm{~kg} / \mathrm{m}^{3}$. For the initial investigation, the mortar specimens provided were unspecified, carbonated lime mortar with an open porosity between $0.26(K-Q)-0.28(A-J) \mathrm{m}^{3} / \mathrm{m}^{3}$, and dry density of $1881(\mathrm{~A}-\mathrm{J})-1941(\mathrm{~K}-\mathrm{Q}) \mathrm{kg} / \mathrm{m}^{3}$. The lime mortar used for the remaining experiments was a $7.7 \%$ lime mortar (air lime) with aggregates of 0-4 mm grain size with an open porosity of $0.33 \mathrm{~m}^{3} / \mathrm{m}^{3}$ and dry density of $1752 \mathrm{~kg} / \mathrm{m}^{3}$.

For the initial investigation, 16 different hydrophobization agents were included; these are presented in Table 1 below. Some of these agents were also used for the further experimentation, which is expressed in the far right column. Most of the agents included in this study are based on silane or siloxane, or a hybrid of both. A few are based on nanotechnology. The silane or siloxane based agents are regarded as pore liners. The pore liners penetrate the open pores of the specimens, and create a hydrophobic lining to the pores without obstructing the vapour diffusion of the material. The agents based on nanotechnology, take advantage of "self-assembly" of the nanoparticles, which is a phenomenon where the particles arrange and assemble themselves in a fashion with the purpose of creating a larger 
Table 1: Hydrophobization agents included in the study, information as stated in technical data sheets of each agents. Highlights in "application method" indicate methods and amounts used for steps 2 and 3.

\begin{tabular}{|c|c|c|c|c|c|}
\hline & $\begin{array}{l}\text { Active component } \\
\text { (concentration of active component) }\end{array}$ & $\begin{array}{l}\text { Liquid/ } \\
\text { cream }\end{array}$ & Application method + coats & $\begin{array}{l}\text { Consumption pr. coat } \\
{\left[1 / \mathrm{m}^{2} \text { or } \mathrm{m}^{2} / \mathrm{g}\right]}\end{array}$ & $\begin{array}{l}\text { Included in } \\
\text { experiments }\end{array}$ \\
\hline A & Siloxane and Fluoro Polymer (16\%) & Liquid & $\begin{array}{l}\text { Roll, paint brush, low-pressure sprayer or } \\
\text { air-less sprayer, } 1-2 \text { coats }\end{array}$ & $0.1-0.2 \mathrm{l} / \mathrm{m}^{2}$ & 1 \\
\hline B & Copolymers (16\%) & Liquid & $\begin{array}{l}\text { Roll, paint brush, low-pressure sprayer or } \\
\text { air-less sprayer, 1-2 coats }\end{array}$ & $0.1-0.2 \mathrm{l} / \mathrm{m}^{2}$ & 1 \\
\hline C & Various fluoric polymers (16\%) & Liquid & $\begin{array}{l}\text { Roll, paint brush, low-pressure sprayer or } \\
\text { air-less sprayer, 1-2 coats }\end{array}$ & $0.1-0.2 \mathrm{l} / \mathrm{m}^{2}$ & 1 \\
\hline D & $\begin{array}{l}\text { Silane, siloxane and Fluoro Polymer } \\
(16 \%)\end{array}$ & Liquid & $\begin{array}{l}\text { Roll, paint brush, low-pressure sprayer or } \\
\text { air-less sprayer, 1-2 coats }\end{array}$ & $0.1-0.2 \mathrm{l} / \mathrm{m}^{2}$ & 1 \\
\hline E & Silane/siloxane (16\%) & Liquid & $\begin{array}{l}\text { Roll, paint brush, low-pressure sprayer or } \\
\text { air-less sprayer, 1-2 coats }\end{array}$ & $0.1-0.2 \mathrm{l} / \mathrm{m}^{2}$ & 1 \\
\hline $\mathbf{F}$ & $\begin{array}{l}\text { Siloxane copolymers and } \\
\text { pefluorinated siloxane (16\%) }\end{array}$ & Liquid & $\begin{array}{l}\text { Roll, paint brush, low-pressure sprayer or } \\
\text { air-less sprayer, 2-3 coats }\end{array}$ & $0.1-0.2 \mathrm{l} / \mathrm{m}^{2}$ & 1 \\
\hline G & $\begin{array}{l}\text { Nanoparticle dispersion, isopropanol } \\
\text { solvent (<13\%wt) }\end{array}$ & Liquid & $\begin{array}{l}\text { Airless standard low-pressure sprayer, roll } \\
\text { or paint brush, min. } 2 \text { coats }\end{array}$ & $0.062-0.075 \mathrm{l} / \mathrm{m}^{2}$ & 1 \\
\hline H & $\begin{array}{l}\text { Nanoparticle dispersion, isopropanol } \\
\text { solvent }(<3 \% \mathrm{wt})\end{array}$ & Liquid & $\begin{array}{l}\text { Roll, paint brush or air-less sprayer, } 2 \\
\text { coats }\end{array}$ & $0.1-0.125 \mathrm{l} / \mathrm{m}^{2}$ & 1 \\
\hline I & Silane $(80 \%)$ & Cream & Roll, paint brush or air-less sprayer, 1 coat & $0.20-0.50 \mathrm{l} / \mathrm{m}^{2}$ & 1 \\
\hline $\mathrm{J}$ & Silane (40\%) & Cream & Roll, paint brush or air-less sprayer, 1 coat & $0.15-0.20 \mathrm{l} / \mathrm{m}^{2}$ & $1,2,3$ \\
\hline K & Unknown & Liquid & $\begin{array}{l}\text { Sponge, paint pad, cotton-cloth or sprayer, } \\
2 \text { coats }\end{array}$ & $0.025-0.1 \mathrm{l} / \mathrm{m}^{2}$ & 1 \\
\hline $\mathbf{L}$ & Chlorophyllane & Liquid & Roll, paint brush or low-pressure sprayer & $0.08-0.17 \mathrm{l} / \mathrm{m}^{2}$ & 1 \\
\hline $\mathbf{M}$ & $\begin{array}{l}\text { Flour-Acryl-Polymer and Alkyl-Acoxy } \\
\text { Silane }\end{array}$ & Liquid & $\begin{array}{l}\text { ND-sprayer with Viton seal, airless sprayer, } \\
\text { roll, paint brush, 1-2 coats }\end{array}$ & $90-170 \mathrm{~g} / \mathrm{m}^{2}$ & 1 \\
\hline $\mathbf{N}$ & Alkylalcoxysilane & Liquid & Brush or low-pressure sprayer, 1-3 coats & $180-230 \mathrm{~g} / \mathrm{m}^{2}$ & 1,2 \\
\hline 0 & Silane $>20 \%$ & Liquid & $\begin{array}{l}\text { Low-pressure sprayer with Viton seal, 2-3 } \\
\text { coats }\end{array}$ & $2-300 \mathrm{~g} / \mathrm{m}^{2}$ & 1 \\
\hline $\mathbf{P}^{*}$ & Silane/siloxane (100\%) & Liquid & Roll, Paintbrush or sprayer, 2 coats & $\begin{array}{l}10-40 \mathrm{~g} / \mathrm{m}^{2} \\
\left(110-440 \mathrm{~g} / \mathrm{m}^{2} \text { diluted }\right)\end{array}$ & 1,2 \\
\hline $\mathbf{Q}$ & Reference & & & & $1,2,3$ \\
\hline
\end{tabular}

${ }^{*}$ Agent $\mathrm{P}$ is a 2-component hydrophobization agent, diluted 1:11 with organic solvent (e.g. mineral turpentine).

For the water migration experiment, 3, some internal insulation materials were applied to the wall sections. These

\begin{tabular}{|l|c|c|c|c|}
\hline Insulation material & Density, $\rho_{d}$ & Thermal conductivity, $\lambda$ & $\begin{array}{c}\text { Water uptake coefficient, } \\
{\left[\mathrm{kg} /\left(\mathrm{m}^{2} \mathrm{~s}^{\prime 2}\right)\right]}\end{array}$ & $\begin{array}{c}\text { Water vapour diffusion } \\
\text { resistance factor, } \mu\end{array}$ \\
\hline
\end{tabular}




\begin{tabular}{|l|c|c|c|c|}
\hline & {$\left[\mathrm{kg} / \mathrm{m}^{3}\right]$} & {$[\mathrm{W} /(\mathrm{mK})]$} & & {$[-]$} \\
\hline Foam concrete $^{*}$ & 147 & $0.057-0.064$ & 0.078 & 2 \\
\hline PUR with CaSi channels $^{* *}$ & 49 & 0.037 & 0.013 & 27 \\
\hline ACC $^{* *}$ & 99 & 0.042 & 0.006 & 7 \\
\hline
\end{tabular}

${ }^{*}$ Material parameters derived from the work by Sandholdt and Dysted [15]

${ }^{* *}$ Material parameters derived from material database of simulation software Delphin 5.8.3 [16]

\subsection{Experimental methods}

In this section the various experimental methods applied will be described.

\subsubsection{Initial investigation}

The initial investigation of 16 different hydrophobization agents (displayed in Table 1) consists of 3 different parts, described in sections $2.2 .1 \cdot 1-2.1 .3$. The hydrophobization agents were applied to the specimens by two different methods. The liquid agents were applied to all sides of the specimens by shaking them in a plastic bag containing the agent for 10 seconds. The creamy products (I and J) were applied with a paint brush, in the amounts recommended by the manufacturer, see Table 1. The brick specimens were whole bricks, as it was desired to study the unbroken, external brick surface's susceptibility to the hydrophobization agents. Standard Danish brick dimensions are $228 \times 108 \times 54 \mathrm{~mm}^{3}$. The carbonated air lime mortar specimens were significantly smaller, and cut from a larger plate. The specimens were on average $93 \times 40 \times 30 \mathrm{~mm}^{3} .1$ specimen of both brick and lime mortar was investigated for each hydrophobization treatment. The specimens were initially oven-dried at $105^{\circ} \mathrm{C}$, and hereafter conditioned in room conditions before the application of hydrophobic treatment. The specimens were hydrophobized 14 days prior to the experimental execution.

The various hydrophobization agents were evaluated by means of a ranking system applied to the 3 categories penetration depth, water uptake and drying, for both brick and mortar. The ranking system is implemented as a very simplified mean for interpreting the various results in the complex field. Penetration depth was ranked according to percentage of half the specimen's thickness, and specimens with full penetration were thus given a score of $100 \%$. The water uptake was ranked by the final mass\% increase by the end of the experiment, as a percentage relative to the reference specimen. The drying was ranked by the percentage difference between the initial slopes of the drying graph for each treatment relative to the reference specimen. The drying experiment is described in section 2.2.1.2. The final ranking score was the sum of the three scores for the 3 categories, and a higher score yielded an overall better performance of this agent. A combined score for brick and mortar consists of the sum of the final score for each material. The formulas used for the ranking system, can be seen below in eq. 1-5; 
1) Penetration depth

2) Water uptake

2a) Mass increase

3) Drying

3a) Initial slope*

$$
\frac{\text { registered penetration depth }}{\frac{\text { specimen thickness }}{2}} \cdot 100
$$$$
\frac{\text { mass }_{\text {increase }} \text { reference }}{- \text { mass } \text { increase }_{\text {specimen }}} \cdot 100
$$$$
\frac{\text { mass }_{\text {end }}-\text { mass }_{\text {initial }}}{\text { mass }_{\text {initial }}} \cdot 100
$$$$
\frac{\text { initial slope }_{\text {reference }}-\text { initial slope }_{\text {specimen }}}{\text { initial slope }_{\text {reference }}} \cdot 100
$$

$$
\frac{y_{2}-y_{1}}{x_{2}-x_{1}}
$$

*The initial slope is calculated based on values from timestep $0\left(x_{1}=0\right)$ to timestep 4020 minutes $\left(x_{2}=4020\right)$

\subsubsection{Water uptake}

The water uptake experiment was performed as full immersion experiments. The treated specimens were weighed and then placed on triangular spacers in a water tank, with a water level above the top of the specimen, as seen in Figure 1. The mass of the specimen was recorded before immersion, and after immersion at the following intervals; $2,4,8,16$, $30,120,180,240,300$ minutes, as well as one final measurement 20-28 hours after immersion. At every weighing, each specimen was dried off with a damp cloth, to avoid hanging water affecting the results. The measurements were transformed into mass\% increase, and plotted in a diagram over time; thus the absorption of each specimen over time can be studied graphically.
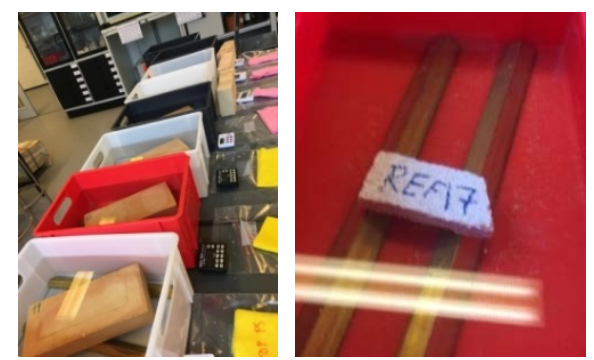

Figure 1: Experimental setup of full immersion water absorption experiments on brick (left) and mortar (right).

\subsubsection{Drying experiment}

After the water absorption experiment has finalized, all treated specimens and reference specimens were saturated by means of vacuum in desiccators (Figure 2) prior to initiating the drying experiment. For the vacuum saturation, boiled and cooled demineralized water was used. Hereafter, the specimens were placed on triangular spacers in a climate chamber of approximately $20^{\circ} \mathrm{C}$ and $85 \%$ relative humidity to dry. The initial drying was monitored with 6 weighings during the first hour, and hereafter one measurement per day or two days was carried out during the duration of 6 

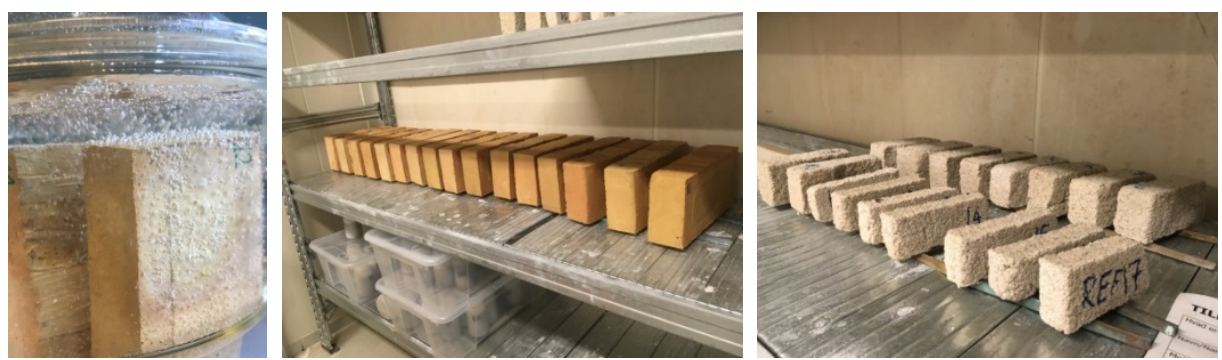

Figure 2: Vacuum saturation of brick in desiccator (left), and drying in climate chamber of brick (middle) and mortar (right).

\subsubsection{Penetration depth}

The specimens were broken in half with a hammer and chisel as seen in Figure 3, and the broken side sprayed with water to visually define the penetration depth of the hydrophobization agents. The penetration depth was measured at 7 evenly distributed locations on both of the long sides, and one location on each short edge. A large penetration depth does not necessarily equal the highest efficiency of water repellent in a hydrophobization agent. With a large penetration depth however, the agent may further prevent deeper water ingress, and e.g. frost damage.
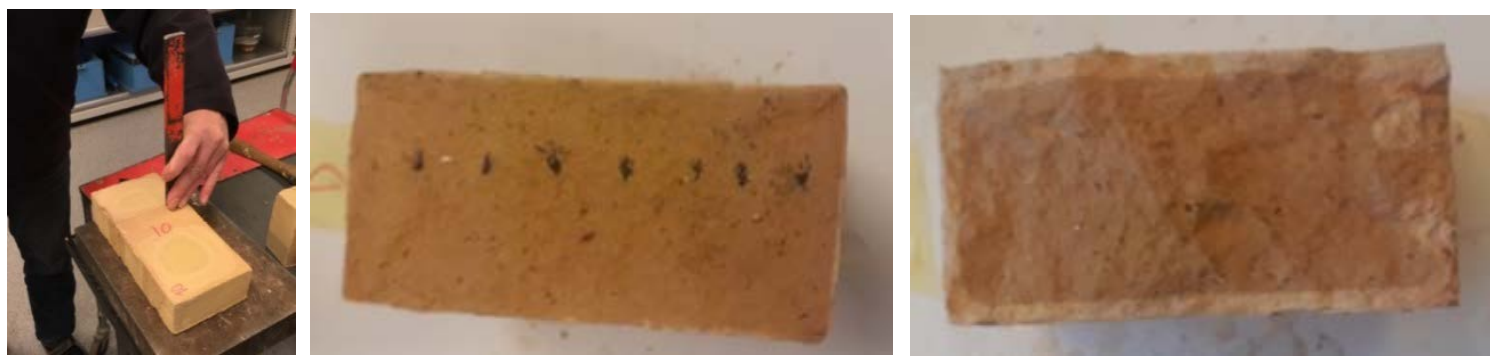

Figure 3: Halving of brick specimens with hammer and chisel (left), marking of 7 measuring locations on both sides (agent L), and example of visible penetration depth, the lighter area around the brick (agent E).

\subsubsection{Influence on vapour diffusion}

Hydrophobization of historic masonry repels liquid water from external sources, such as wind-driven rain. However, the façade will not be protected from internal moisture sources, in the form of warm, moist air, or possible condensation, why the vapour diffusivity of a hydrophobized wall should not be affected by the treatment. This is investigated by the cup experiment (wet cup) for measurement of water vapour diffusion resistance factor of untreated and hydrophobized specimens of both brick and mortar. For this experiment, 3 agents $(\mathrm{J}, \mathrm{N}$ and $\mathrm{P}$ ) were examined on 3 specimens with each agent, in addition to 3 reference specimens of both brick and mortar. Prior to the experiment the specimens were cut into $\varnothing 80 \mathrm{~mm}$ specimens and sealed in $\varnothing 100 \mathrm{~mm}$ plastic rings designed for the cups. Mortar specimens were sealed in a 
plastic ring with silicone, and the brick specimens were sealed with epoxy, as seen in Figure 4 . The specimens were hydrophobized on the top side against the measurement chamber, with the recommended application methods; the liquid agents, $\mathrm{N}$ and $\mathrm{P}$, were applied with a sprayer, and the cream, J, in the amounts and layers (J: 1 layer, N: 3 layers, P: 2 layers) as specified in the datasheets. Specimens were weighed before and after application of each layer, and the specific amounts are presented in Table 3.

Table 3: Applied hydrophobization agent on test specimens for water vapour diffusion experiment.

\begin{tabular}{|c|c|c|c|c|c|c|c|}
\hline & \multicolumn{6}{|c|}{ Consumption of hydrophobization agent [g] } & \multirow{3}{*}{$\begin{array}{l}\text { Producer specified } \\
\text { consumption pr. layer [g] }\end{array}$} \\
\hline & \multicolumn{3}{|c|}{ Brick } & \multicolumn{3}{|c|}{ Mortar } & \\
\hline & Layer 1 & Layer 2* & Layer 3* & Layer 1 & Layer 2* & Layer 3* & \\
\hline $\mathrm{J} 1$ & 1 & - & - & 1,3 & - & - & \\
\hline $\mathrm{J} 2$ & 0,9 & - & - & 1,5 & - & - & $\sim 0.8$ \\
\hline $\mathrm{J} 3$ & 1,1 & - & - & 1,5 & - & - & \\
\hline N1 & 1,1 & 1,2 & 1,2 & 1,3 & 0,9 & 1,2 & \\
\hline N2 & 1,3 & 1,1 & 1,3 & 1,1 & 1 & 1,6 & $\sim 0.9-1.1$ \\
\hline N3 & 1,2 & 1,2 & 1 & 1,2 & 1,2 & 1,3 & \\
\hline P1 & 1,3 & 1,3 & - & 1,1 & 0,9 & - & \\
\hline P2 & 1,3 & 1,1 & - & 1,4 & 0,9 & - & $\sim 0.5-2.0$ \\
\hline P3 & 1,2 & 1,1 & - & 1,1 & 1 & - & \\
\hline
\end{tabular}

226 The experiment was carried out according to DS/EN ISO 12572 - Hygrothermal performance of building materials and products - Determination of water vapour transmission properties. The principle of the experiment is sealing a specimen in a cup containing an aqueous saturated solution, in this case $\mathrm{KNO}_{3}(94 \%$ relative humidity). The cup was placed in a climate chamber with controlled temperature $\left(23^{\circ} \mathrm{C}\right)$ and relative humidity $(50 \%)$ conditions. Due to different partial vapour pressures on both sides of the specimen vapour flow occurs, and by daily weighings for a week, the rate of water vapour transmission in steady state can be determined, and further transformed into water vapour diffusion resistance factor, $\mu$. Figure 4 illustrates the specimen preparation and experimentation. 

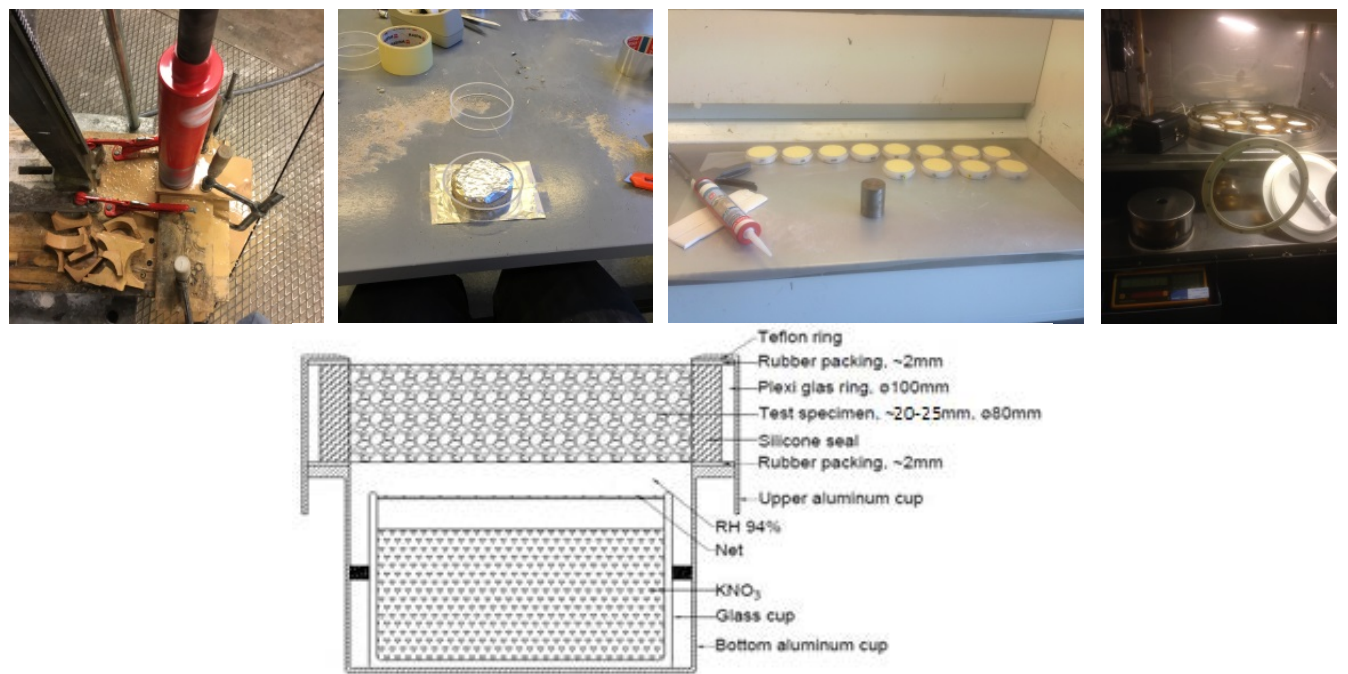

Figure 4: Top row: Preparation of specimens for cup experiment; brick cutting with a core drill, sealing lime mortar specimen in plexi glas rings with silicone, specimens in cups placed in climate chamber (right). Bottom: Illustration of the specimen in the specially designed cup.

\subsubsection{Water migration through masonry}

One of the hydrophobization agents included in the initial investigation was tested in a larger perspective. The experimental method was chosen with the purpose of monitoring the resulting hygrothermal behavior of solid masonry with and without hydrophobization, when exposed to typical climatic loads. To imitate the dynamics and the varying nature of the natural climate, a cyclic exposure was designed. The hydrophobization was applied with a paint brush and in amounts according to specifications [17]. The investigation of water migration was performed to study the effect of hydrophobization within masonry walls rather than with the masonry components individually. The experiment was conducted on nine $1 \frac{1}{2}$ brick thick solid masonry wall sections of $330 \times 348 \mathrm{~mm}^{2}$ built into the doors of 3 refrigerators, as seen in Figure 5. Each wall section was surrounded by a vapour barrier tightly taped to the perimeter, to ensure adiabatic boundaries. Furthermore, the boundaries of the wall surface were sealed with silicone, to prevent water penetration through small airgaps at the perimeter. To prevent excess water influencing neighboring wall sections, gutters were incorporated for each wall section $100 \mathrm{~mm}$ of the various insulation materials were applied to the internal side of the wall section, with the exception of the reference wall, which was uninsulated. Each wall section was built up as seen in Figure 5. For registration of the temperature and relative humidity in the wall sections as well as in the refrigerator itself (cold climate) HYT-221 sensors were used. The sensors were placed in drilled holes that were subsequently sealed with silicone. Each sensor was set for logging measurements every 5 minutes during the experiment, and the data was logged directly to a computer for data storage. The placements of each sensor are also seen in Figure 5. Vertically, the sensors were placed in the middle of each wall section. The sensors logged temperature and relative humidity. 

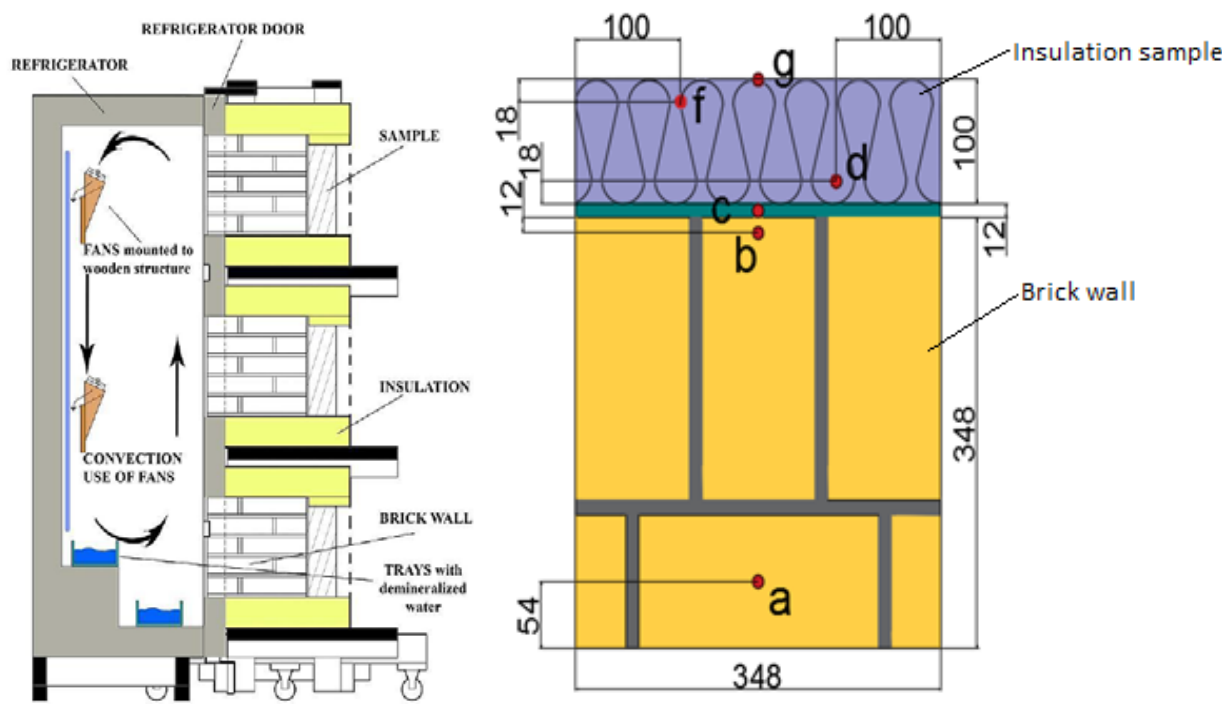

Figure 5: Left: Diagram of the experimental setup with the cooling chamber from Sandholdt et al. [15]. Right: Construction of each wall section, and sensor location. Dimensions are stated in [mm]. Sensor locations are denoted a, b, c, d, f, and g.

As mentioned, there are 3 wall sections in each of the 3 refrigerator doors. Table 4 displays the setup of each wall section, with insulation types, as well as whether or not hydrophobization was applied. In the table, it is seen that each wall section is denoted with 1.1-1.3, 2.1-2.3, and 3.1-3.3, depending on the refrigerator door, and the height. Furthermore, the table states which sensor locations were in use for each wall section.

Table 4: Overview of wall sections 1) insulation sample type, 2) with/without hydrophobization, 3) internal surface treatment, 4) sensors used in this wall section. Placements of the sensors are shown in Figure 5 right.

\begin{tabular}{|c|c|c|c|c|c|}
\hline 1.1 & & 2.1 & & 3.1 & \\
\hline 1) & Foam concrete & 1) & Insulation type: PUR with CaSi & 1) & Insulation type: ACC \\
\hline 2) & Hydrophobization & & channels & 2) & No hydrophobization \\
\hline 3) & Internal: Diffusion open paint & 2) & Hydrophobization & 3) & Internal: Diffusion open paint \\
\hline 4) & $a, b, c, d, f$ & 3) & $\begin{array}{l}\text { Internal: No treatment } \\
a, b, c, g\end{array}$ & 4) & $a, b, c, d, f$ \\
\hline 1.2 & & 2.2 & & 3.2 & \\
\hline 1) & Insulation type: No insulation (ref) & 1) & Insulation type: Foam concrete & 1) & Insulation type: ACC \\
\hline 2) & No hydrophobization & 2) & No hydrophobization & 2) & Hydrophobization \\
\hline 3) & Internal: No paint (ref) & 3) & Diffusion open paint & 3) & Internal: Diffusion open paint \\
\hline 4) & $a, b, c$ & 4) & $a, b, c, d, f$ & 4) & $a, b, c, d, f$ \\
\hline 1.3 & & 2.3 & & 3.3 & \\
\hline 1) & Insulation type: Foam concrete & 1) & Insulation type: Foam concrete & 1) & Insulation type: PUR with CaSi channels \\
\hline 2) & Hydrophobization & 2) & No hydrophobization & 2) & No hydrophobization \\
\hline 3) & Internal: Ordinary paint & 3) & Internal: Ordinary paint & 3) & Internal: No treatment \\
\hline 4) & $a, b, c, d, f$ & 4) & $a, b, c, d, f$ & 4) & $a, b, c, g$ \\
\hline
\end{tabular}

The diffusion open paint system is a combination of a primer and a silicate based paint $\left(s_{d}<0.01 \mathrm{~m}\right)$, whereas the ordinary paint used was a standard acrylic paint $\left(\mathrm{s}_{\mathrm{d}}<0.18 \mathrm{~m}\right)$.

\subsubsection{Boundary conditions}

The experiment was conducted in a laboratory. Measurements from a sensor placed at internal surfaces of the walls, represent the interior conditions that were found to be steady with a temperature of $22-23^{\circ} \mathrm{C}$ and relative humidity of 
$55-60 \%$. The minor fluctuations in the internal hygrothermal conditions are not thought to impact the experimental results obtained. The experiment was conducted in 24 hour cycles. Each 24 hour cycle consisted of 30 minutes of rain, 2 hours of solar radiation, and $21 \frac{1}{2}$ hours of cold climate. This cycle was repeated 5 times.

The rain loads were applied to the wall sections by means of a purposely designed test stand, seen in Figure 6 , C. A perforated (holes of $\varnothing 0.5 \mathrm{~mm}$ pr. $50 \mathrm{~mm}$ ) $340 \mathrm{~mm}$ long pipe in the length of each wall section was placed at the top, and provided a horizontal water load of $0.08-0.11 \mathrm{l} / \mathrm{min}$. The water distribution was therefore more direct than actual rain, but the intention here was also to create severe climatic conditions. By Danish meteorological standards, a severe cloud burst rain storm is defined as a rain intensity of $15 \mathrm{~mm}$ in 30 minutes or less [18]. This corresponds to $30 \mathrm{~mm} / \mathrm{h}$, or $30 \mathrm{l} / \mathrm{m}^{2} \mathrm{~h}$. The provided water load of approximately $0.1 \mathrm{l} / \mathrm{min}$ thus represents a severe cloudburst of $50 \mathrm{~mm} / \mathrm{h}$, corresponding to each wall being subjected to 3 liters of water over 30 minutes.

The solar radiation loads were provided by Osram ULTRA-VITALUX $300 \mathrm{~W}$ bulbs for simulation of heat and UV-radiation. to the center of each wall section. The distance between the bulbs and the wall sections was determined by the socalled black panel temperature. In order to achieve a black panel temperature of $75 \pm 5{ }^{\circ} \mathrm{C}$, the distance between the wall and the bulb was set at $20 \mathrm{~cm}$, yielding an average black plate temperature of $78.1^{\circ} \mathrm{C}$.
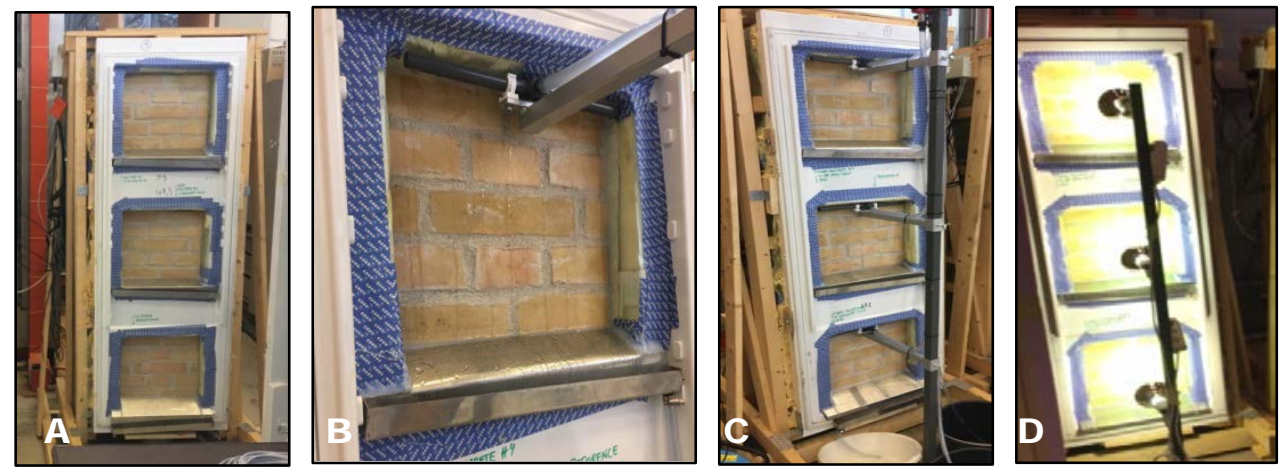

Figure 6: Experimental setup. A: 3 wall sections in mounted in a refrigerator door. B: water loads applied horizontally to the top of the wall section, by perforated pipe. C: view of water loads applied to 3 wall sections. D: radiation loads on 3 wall sections.

As mentioned, the wall sections were built into the doors of refrigerators, and these refrigerators provided the cold climate. The refrigerator doors with the wall sections were mounted on wooden rigs that were supplied with hinges. These hinges and the original rubber gaskets on the doors were utilized to ensure a tight fit to the original refrigerator. 
When the refrigerators/cold climate assimilators were not in use, the opening was covered with XPS plates to help maintain the cold climate conditions inside. The temperature in the refrigerators was controlled by a temperature regulated on/off switch, Sygonix ${ }^{\circledR}$ room thermostat, which was set to a temperature of $3^{\circ} \mathrm{C}$, and set to switch on at 3.2 ${ }^{\circ} \mathrm{C}$ and off at $2.8^{\circ} \mathrm{C}$. The original thermostat was moved outside of the refrigerator, to induce constant cooling until switching off by the Sygonix ${ }^{\circledR}[15]$. The relative humidity was less controlled, however kept high by having a water bath inside the refrigerator. The conditions were monitored, and by the above mentioned means it was possible to keep the temperature at $4{ }^{\circ} \mathrm{C}$ and the relative humidity at $80-85 \%$, interrupted only when moving the refrigerators to provide water and radiation loads. The conditions in the refrigerator were kept steady and stratification avoided by mounting four fans inside each refrigerator for constant air circulation.

\section{Results}

\subsection{Initial investigation}

Results from the experiments included in the initial investigation, are presented in sections 3.1.1-3.1.3.

\subsubsection{Water uptake}

Results from the water uptake experiments are displayed in Figure 7 and Figure 8 for brick and mortar respectively. For the brick specimens, a large difference in water absorption was observed. After 300 minutes, agents $A, B, C, D, K$ and $L$ had reached saturation to the same degree as the reference specimen Q. Agents $\mathrm{F}$ and $\mathrm{H}$ followed closely with initial absorption, but took the durance of the experiment to reach saturation. Agents $G$ and $P$ are in the middle of the absorption range, and finally agents $\mathrm{E}, \mathrm{I}, \mathrm{J}, \mathrm{M}, \mathrm{N}$ and $\mathrm{O}$ have a mass increase of less than $2 \%$ during the duration of the experiment, and are thus deemed to be the most successful agents in regards to low water uptake. 


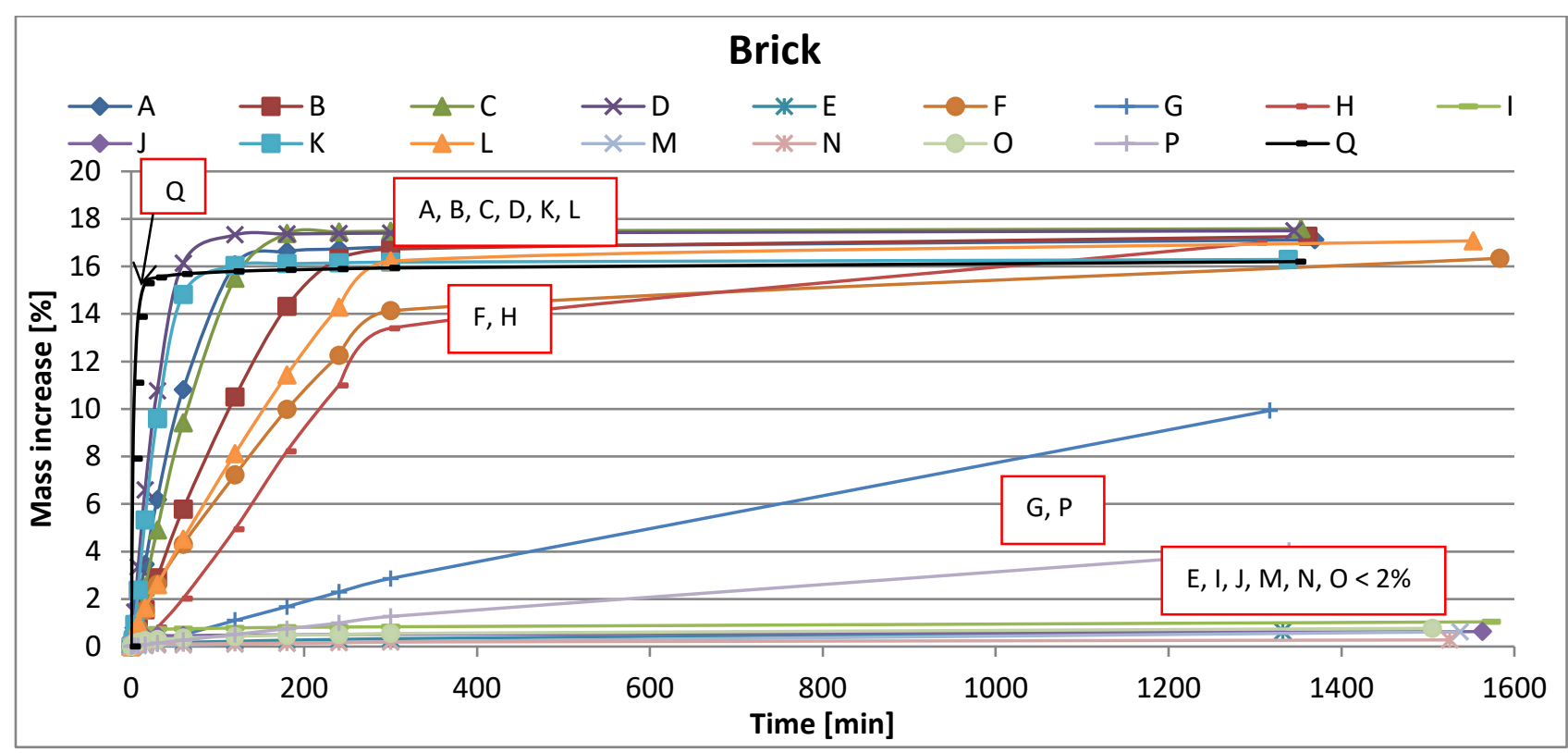

Figure 7: Mass increase by full immersion over time for brick specimens with hydrophobization agent A-P. Q is reference specimen.

For the mortar specimens, the results seem more random for the various agents. However, as can be seen in Figure 8 , treatments $\mathrm{N}$ and $\mathrm{O}$ seem to have no effect on the mortar, as they quickly absorb the same amount of water as the reference specimen. Agents $M$ and $P$ gain less than $2 \%$ mass during the duration of the experiment, and agents $E, G, H$ and $\mathrm{K}$ gain less than $5 \%$ mass during the experiment.

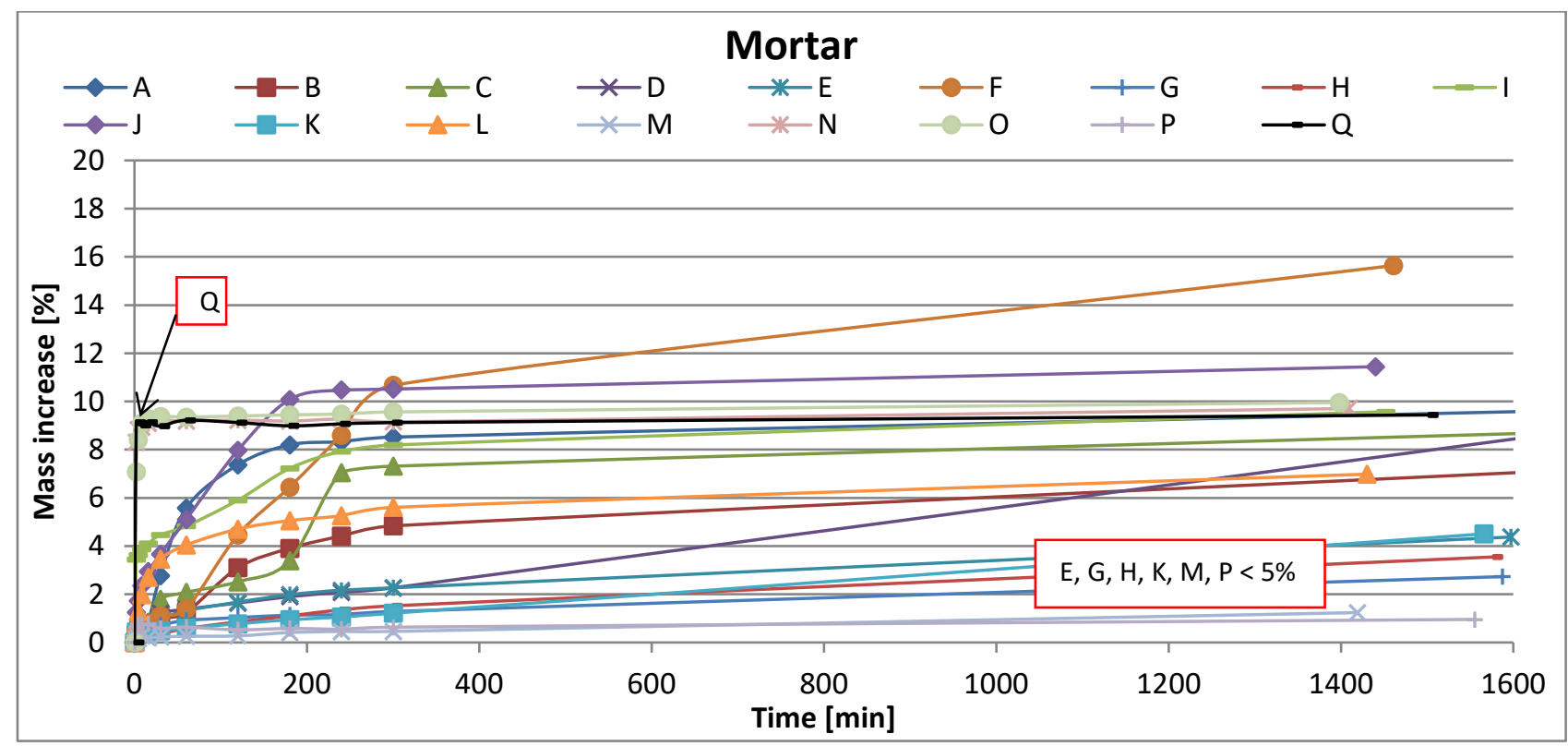

Figure 8: Mass increase by full immersion over time for mortar specimens with hydrophobization agent A-P. Q is reference specimen. 
Figure 9 distinctly shows the effectiveness of the various hydrophobization agents, and it is clear that there is relatively no mass increase in brick specimens treated with $E, I, J, M, N$ and $O$, all silane based except $E$ which is a hybrid. For the mortar specimens, the largest effect of hydrophobization is seen from agents $M$ and $P$, silane based and hybrid.

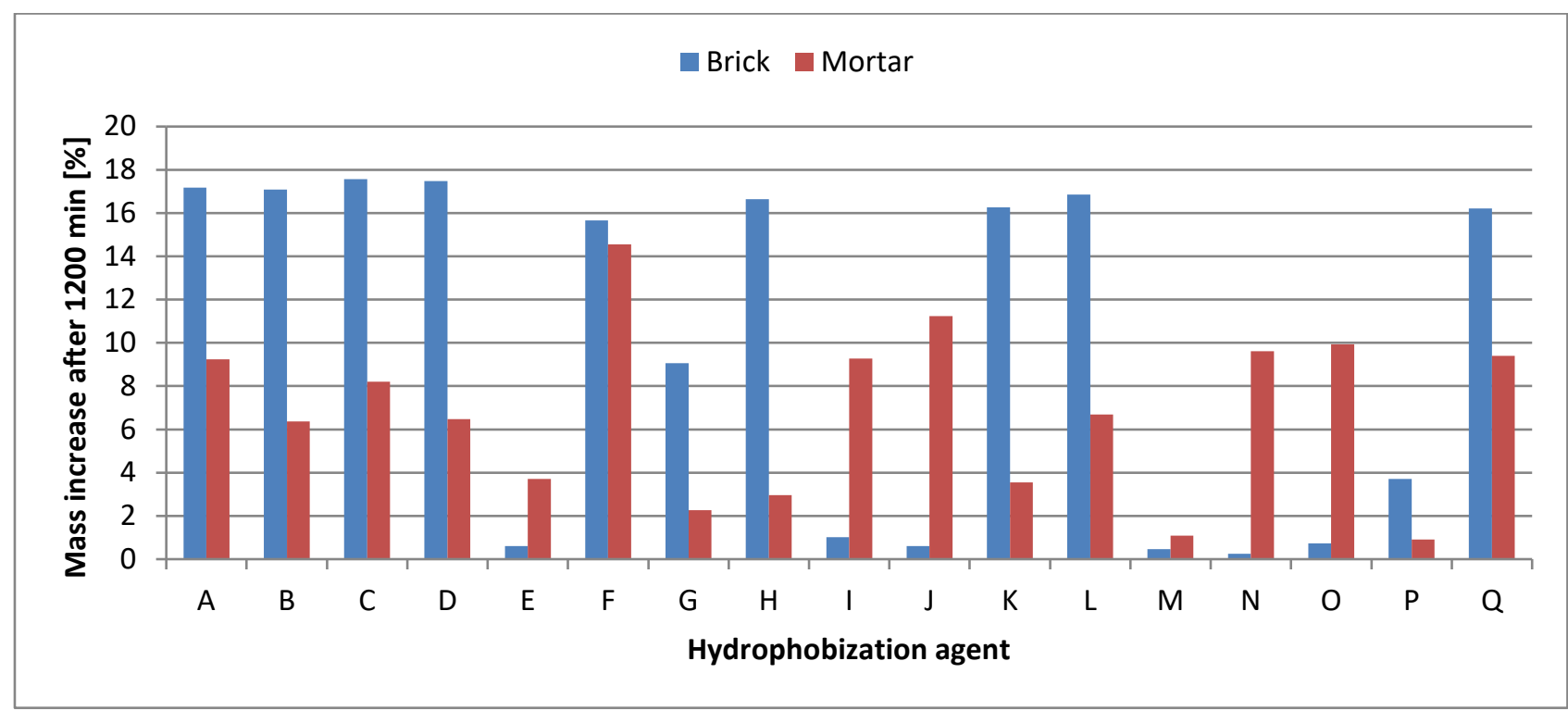

Figure 9: Bar chart of the mass increase of each specimen after 1200 minutes of full immersion. $Q$ is reference specimen.

\subsubsection{Drying experiment}

The results from the drying experiments are shown in Figure 10 and Figure 11 below. To the right, the initial drying period is shown as a section, where all the specimens' initial moisture content is adjusted, for a better visualization of the various slopes for different hydrophobization agents. The initial slopes of the drying curves are especially interesting, as this is where liquid transport to the surface occurs. Actual rain events are assumed not to yield vacuum saturated materials however.

It can be seen that brick specimens, $\mathrm{A}, \mathrm{I}, \mathrm{J}, \mathrm{N}$, and $\mathrm{O}$ have the fastest initial drying, and several specimens showed a faster drying than the reference. In terms of long-term drying, brick specimens with agents $A, B, C, D, F, H, K, M, N$ and O reach levels of relatively constant moisture content, and are all less than $1 \%$ moisture content. In regards to mortar specimens, the initial drying is most rapid in specimens with agents $H, K, L, N$ and $O$. 

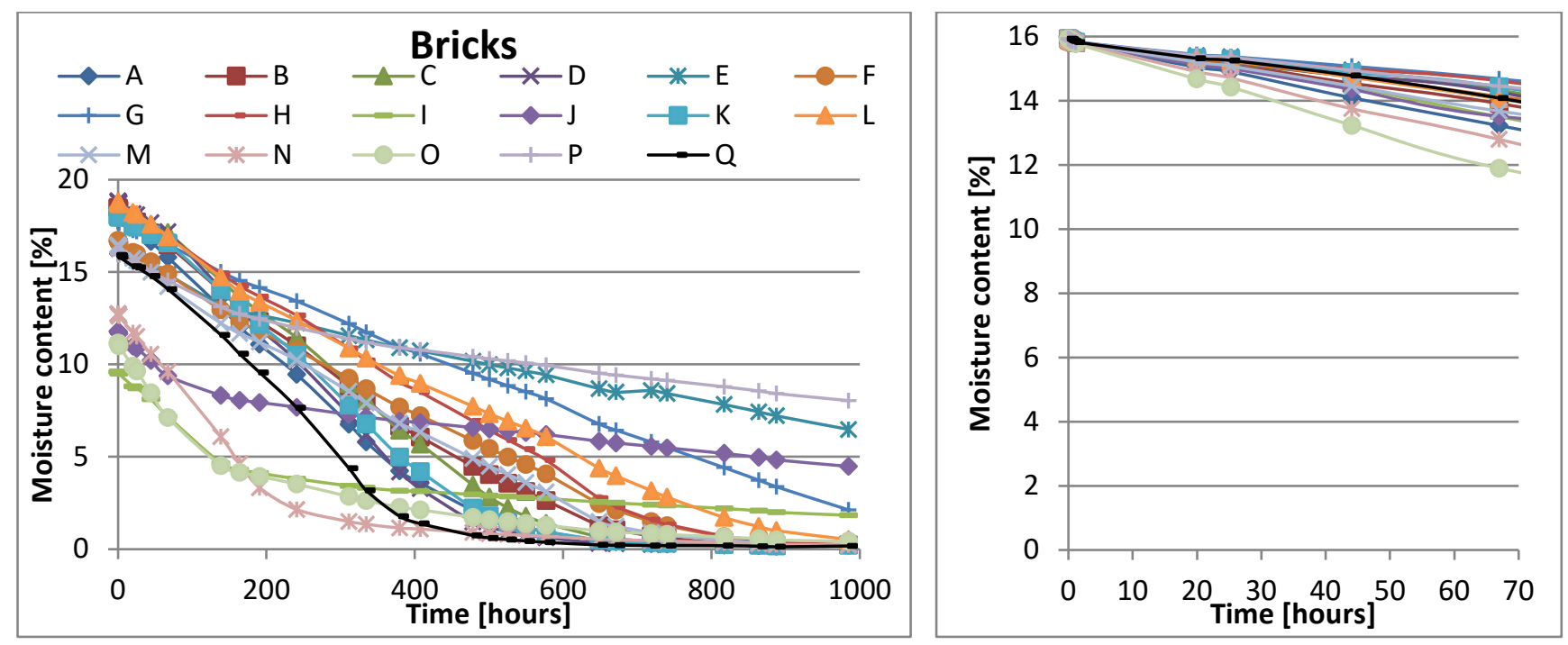

Figure 10: Moisture content reduction of brick during drying time in climate chamber. Right: All moisture contents are adjusted to the same initial moisture content.
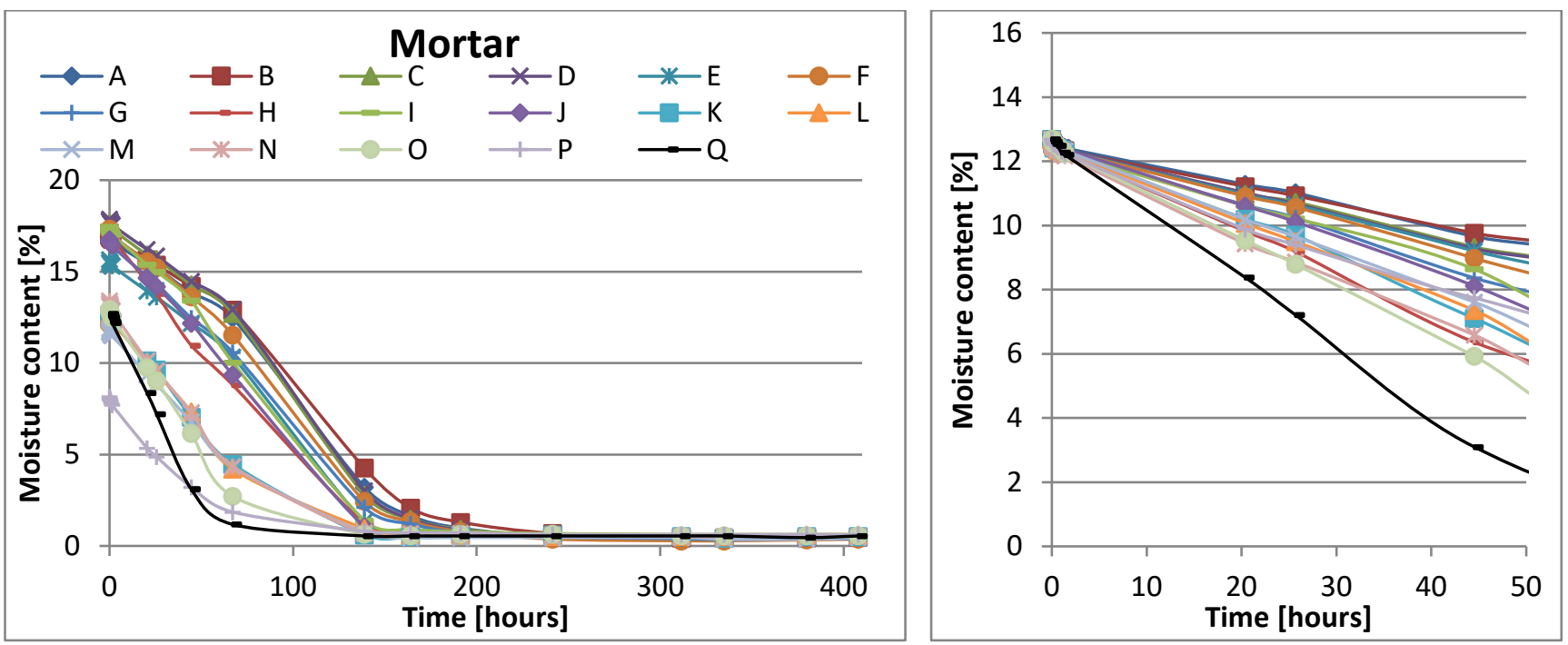

Figure 11: Moisture content reduction of mortar during drying time in climate chamber. Right: All moisture contents are adjusted to the same initial moisture content.

In Table 5 an overview of the different initial slopes can be seen. The drying slopes for the mortar specimens are generally higher than those for the brick specimens. All the mortar specimens show slower drying compared to the reference, while there is much more variation in the drying velocity in brick specimens, as some bricks (A, B, I, J, L, M, $\mathrm{N}, \mathrm{O}$ ) exhibit faster initial drying than the reference, and the rest of the specimens show slightly slower initial drying.

Table 5: Initial slopes of the various drying curves, generated for the first 67 hours of the experiment for brick, and 45 hours for mortar specimens.

\begin{tabular}{|l|c|c|c|c|}
\hline Hydrophobization agent & \multicolumn{2}{|c|}{ Brick } & \multicolumn{2}{c|}{ Mortar } \\
\hline & Initial slope & Relative to reference [\%] & Initial slope & Relative to reference [\%] \\
\hline A & $-0,0403$ & 47 & $-0,0681$ & -68 \\
\hline B & $-0,0301$ & 9 & $-0,0658$ & -69 \\
\hline
\end{tabular}




\begin{tabular}{|l|c|c|c|c|}
\hline C & $-0,0239$ & -13 & $-0,0755$ & -65 \\
\hline D & $-0,0248$ & -10 & $-0,0767$ & -64 \\
\hline E & $-0,0225$ & -18 & $-0,0783$ & -64 \\
\hline F & $-0,0268$ & -3 & $-0,0833$ & -61 \\
\hline G & $-0,0186$ & -32 & $-0,0972$ & -55 \\
\hline H & $-0,0196$ & -29 & $-0,1421$ & -34 \\
\hline I & $-0,0362$ & 31 & $-0,0910$ & -58 \\
\hline J & $-0,0361$ & 31 & $-0,1028$ & -52 \\
\hline K & $-0,0223$ & -19 & $-0,1254$ & -42 \\
\hline L & $-0,0279$ & 1 & $-0,1197$ & -44 \\
\hline M & $-0,0336$ & 22 & $-0,1141$ & -47 \\
\hline N & $-0,0468$ & 70 & $-0,1371$ & -36 \\
\hline O & $-0,0602$ & 118 & $-0,1520$ & -29 \\
\hline P & $-0,0220$ & -20 & $-0,1111$ & -48 \\
\hline Q (ref) & $-0,0276$ & - & $-0,2154$ & - \\
\hline
\end{tabular}

\subsubsection{Penetration depth}

The average penetration depth of the hydrophopization agent is presented below, in Table 6 and in Figure 12 as a percentage of half the specimen thickness. It is seen that for both brick and mortar, agents I and J, which are both silane based, creamy agents, have high penetration depths. Furthermore, agents E, F, G, and L (hybrid, siloxane, nanotechnology and chlorophyllane) have high penetration depths in the mortar samples. Brick specimens with agent $\mathrm{N}$ and $\mathrm{O}$, both silane based, leave an undefinable pattern of a dark/wet ring around the edges when compared to other samples, rather than being dry. However no water absorption in the specimen yields the conclusion of almost full penetration; see Figure 13-Figure 15.

Table 6: Penetration depth [mm].

\begin{tabular}{|l|r|r|}
\hline & Brick & Mortar \\
\hline A & 2,1 & 2,6 \\
\hline B & 1,9 & 4,6 \\
\hline C & 0,7 & 5,6 \\
\hline D & 0,9 & 6,6 \\
\hline E & 5,1 & 16,0 \\
\hline F & 2,0 & 13,0 \\
\hline G & 1,6 & 16,2 \\
\hline H & 1,7 & 3,4 \\
\hline I & 17,6 & 15,4 \\
\hline J & 11,4 & 16,1 \\
\hline K & 1,2 & 3,3 \\
\hline L & 0,9 & 10,9 \\
\hline M & 2,7 & 5,0 \\
\hline N & 26,7 & 1,1 \\
\hline O & 27,1 & 2,0 \\
\hline P & 5,4 & 1,7 \\
\hline Q & 0,0 & 0,0 \\
\hline
\end{tabular}

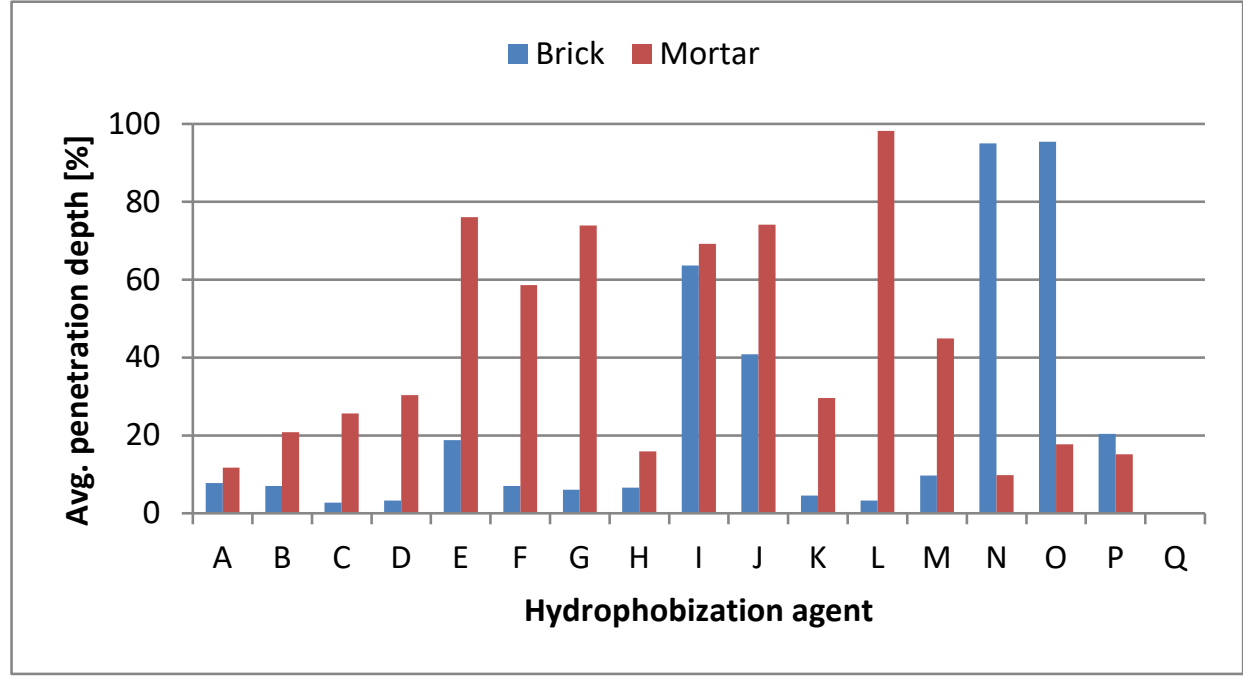

Figure 12: Penetration depths, presented as percentage of $1 / 2$ specimen thicknesses.

Figure 13, Figure 14 and Figure 15 illustrate three examples of penetration depth in brick and mortar of agent I, F and $O$ respectively. The difference in penetration depth in the brick specimens was very apparent. For the brick specimen with agent $F$, there was only a thin, external line of dry material, whereas agent I was seen to penetrate deep into the 

penetration of agent $\mathrm{F}$ on the mortar sample was very uneven.

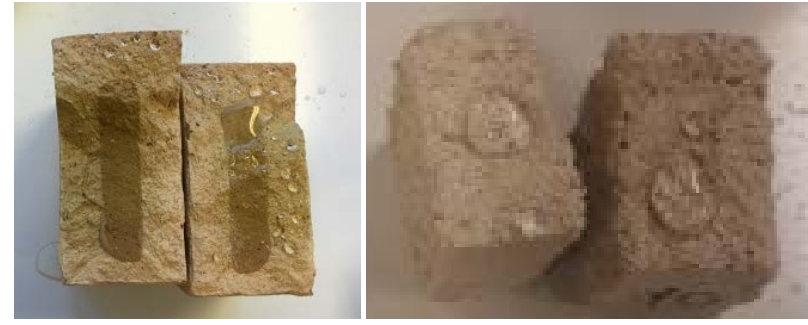

Figure 13: Penetration depth of agent I on brick and mortar.
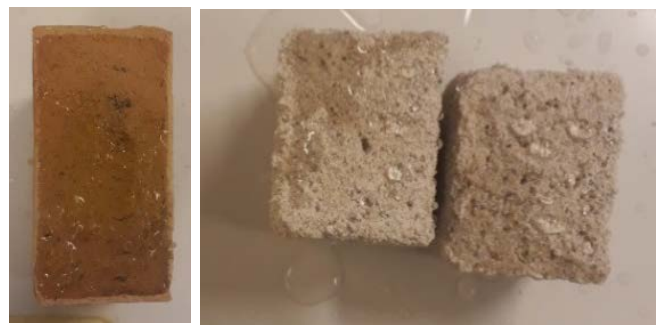

Figure 14: Penetration depth of agent F on brick and mortar.
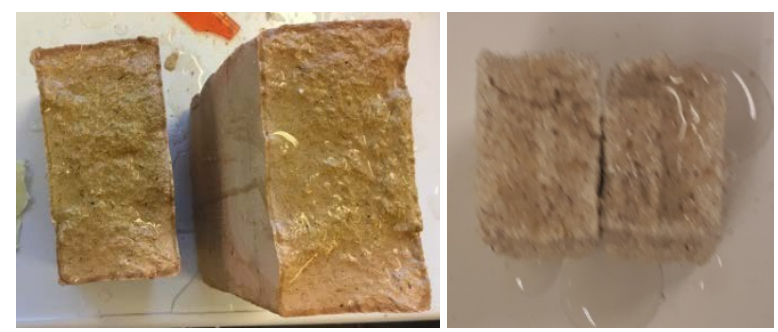

Figure 15: Penetration depth of agent $\mathrm{O}$ on brick and mortar.

\subsection{Influence on vapour diffusion}

Results from the water vapour diffusion experiment are seen in Table 7 and Figure 16 as average values for the three specimens of each type, and standard deviation is presented. It can be seen that the water vapour diffusion resistance factor was not affected significantly by the three investigated hydrophobization treatments. There is however, a slight tendency of reduced water vapour diffusion resistance factor with the application of hydrophobization treatment. This tendency is attributed to uncertainties in the experiment. 
Table 7: Average water vapour diffusion resistance factor and standard deviation.

\begin{tabular}{|l|r|l|}
\hline & $\mu$ & $\begin{array}{l}\text { Standard } \\
\text { deviation } \\
{[-]}\end{array}$ \\
\hline Brick Q, reference & 12.7 & 1.0 \\
\hline Mortar Q, reference & 7.7 & 1.2 \\
\hline Brick J & 12.2 & 2.8 \\
\hline Mortar J & 7.7 & 1.1 \\
\hline Brick N & 11.7 & 0.7 \\
\hline Mortar N & 5.5 & 2.0 \\
\hline Brick P & 11.5 & 1.3 \\
\hline Mortar P & 6.7 & 0.9 \\
\hline
\end{tabular}

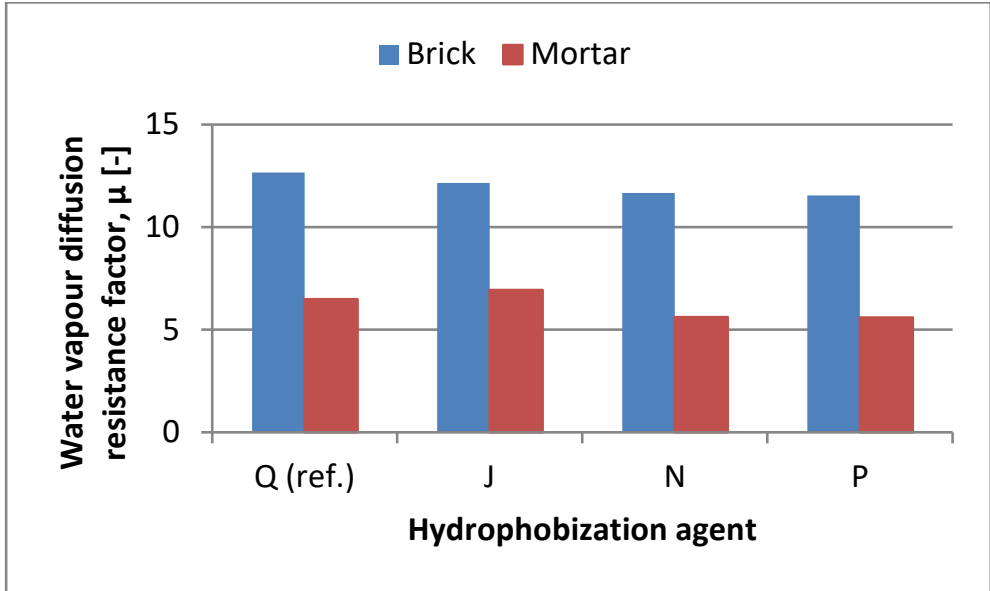

Figure 16: Graphical illustration of water vapour diffusion resistance factor on specimens with no treatment (Q) and treatments J, N and P.

\subsection{Water migration through masonry}

Studying the relative humidity in points A, B, C, and D, presented in Table 8, the effects of hydrophobization was clear - especially in point A. The relative humidity in point A, for untreated masonry, reached $100 \%$, and stayed at this level for the duration of the experiment, whereas for hydrophobized specimens, the relative humidity only exceeded $70 \%$ in short peaks when the water loads were applied. When studying the migration of moisture through the wall, it was seen that the relative humidity increased in all the sensor points during the experiment. In point $D$ however, the relative humidity for all the cases seemed to reach individual maximum limits of $40-75 \%$ that were not further affected by the climatic loads. It was seen that the hydrophobized walls 1.3 and 2.1 had the lowest relative humidities monitored in points $B, C$ and $D$ (although the sensor $D$ was missing for wall 2.1). In these points, the hydrophobized walls 1.1 and 3.2 had conditions resembling the untreated walls. These two walls both had diffusion open paint on the interior side, indicating more influence from interior conditions. Unfortunately, walls 2.1 and 3.3 did not have internal surface treatment. However, 1.3 had ordinary paint, which left it less susceptible to the indoor climate, and thus resulted in the lower relative humidity. Wall 2.2 with diffusion open paint, also exhibited higher RH in points B, C and D compared to 2.3 with ordinary paint. The same tendency applies to wall 3.1 that also had ordinary paint on the internal surface. At the critical point $C$, the interface between internal insulation and masonry, the relative humidities seemed to be continually increasing, with the exception of the hydrophobized walls 1.3 and 2.1. The unhydrophobized wall 3.3 without internal surface treatment yielded a lower relative humidity, also when compared to the hydrophobized walls 1.1 and 3.2. Both the hydrophobized and unhydrophobized wall with insulation of PUR with capillary active channels (2.1 and 3.3), seemed to generate some of the lowest relative humidities at point C, likely due to the capillary active 
properties, despite the fact that the foam concrete exhibited both a higher water uptake coefficient and a lower vapour diffusion resistance factor.

Table 8: Relative humidity [\%] measured in points A, B, C and D. Hydrophobized cases are presented with dashed lines.
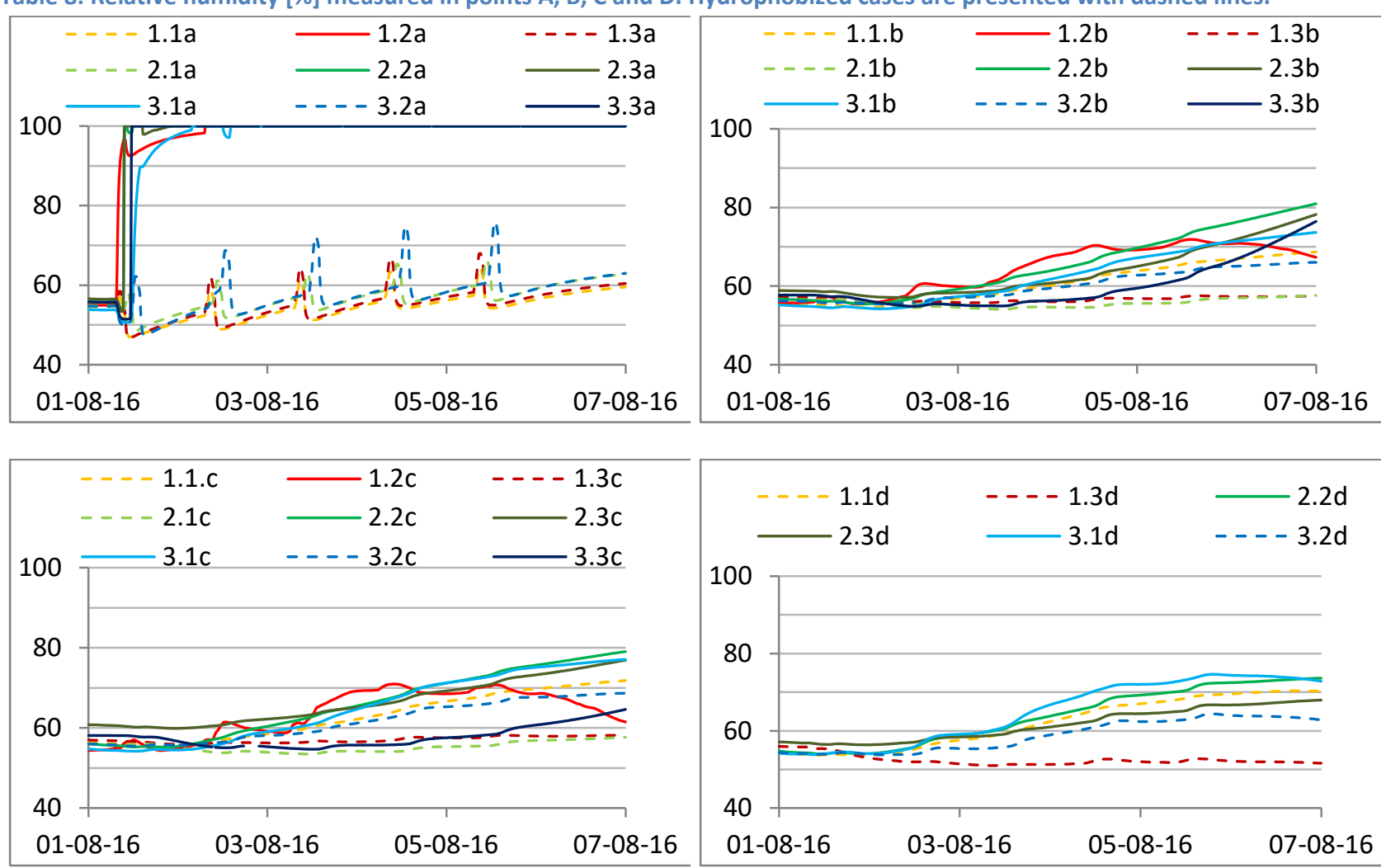

\section{Discussion}

It should be noted, that for the initial investigation, agent $P$ was not diluted, as this was unknown information at the time. Agent P was developed for calcareous materials; however the erroneous application may be the reason for the less pronounced effect on lime mortar. As previously mentioned, specimens were vacuum saturated with hydrophobization agent on the drying surfaces prior to the drying experiment. As seen in Figure 10 and-Figure 11 , brick specimens with agents I, J, N, and O did not reach the same saturation as other specimens. The vacuum saturation of these specimens was repeated to check for error in the saturation procedure. There was no error however, and the explanation was found during the penetration depth experiment. These silane based agents simply penetrated the brick to such an extent that there was less room for water in the pores. It could also had been, that despite the vacuum, these agents blocked the saturation, as they all exhibited low water absorption $(<2 \%)$ as well. The high penetration depth and effectiveness exhibited by agents I and J, may be attributed to the application method, as these creamy agents were 
applied with a paint brush and in specified amounts, as opposed to the liquid agents which were applied to specimens by a 10 second exposure. The 10 second exposure time was applied in order to achieve equal hydrophobization on all sides, and to be able to gain the same curing periods for all sides. The method cannot be applied in reality; however e.g. spraying for 10 seconds is in fact a rather long time frame. The application method does, however, give basis for the comparative study. In regards to mortar specimens, it should be noted that specimens K, L, M, N, O, P, and Q had a slightly lower porosity (as specified in section 2.1), also yielding these specimens a lower degree of saturation compared to other specimens. The water uptake experiment took place for 24 hours, and naturally it is not assumed that an actual rain event will strain a façade to the same degree, however, the experiment was conducted for the purpose of comparison between the different agents. Only one specimen of each agent, on brick and mortar, respectively, were investigated in the initial investigation, yielding the possibility of error, or erroneous results due to minor varieties in the samples. Also, a masonry wall will never undergo the same level of saturation as the vacuum saturated specimens prior to the drying experiment did. In reality, a wall would be much less saturated. The vacuum saturation was performed to achieve a similar moisture content basis. For all of the experiments there are sources of error connected to measurement equipment and human error. For experiments with weight and dimension registration, the scale and caliper both have limitations. Scales used for the drying experiment were only $\pm 0.1 \mathrm{~g}$, for the water uptake experiment the precision was $\pm 0.01 \mathrm{~g}$, and for the investigation of influence on vapour diffusion, a $\pm 0.001 \mathrm{~g}$ scale was used. The caliper used for determination of specimen dimensions was 2 decimals. All specimens, especially mortar specimens, were irregular and the square (water uptake, drying and penetration depth) and round shapes (vapour diffusion) were assumed for determination of dimensions. As the errors should be the same for all specimens in this comparative analysis, the effect of the errors is neglected. The sensors used in the investigation of water migration through masonry had an accuracy of $\pm 1.8 \% \mathrm{RH}$ and $\pm 0.2^{\circ} \mathrm{C}$.

For water absorption experiments on brick specimens, the best performances were seen in agents $E, I, J, M, N$, and $O$, which were primarily silane based agents and one hybrid. For specimens of lime mortar, the effectiveness of the different agent types was not pronounced, as the best performers were a variety of types (silane, hybrid and nano). The drying experiment showed that brick specimens $\mathrm{A}, \mathrm{I}, \mathrm{J}, \mathrm{N}$, and $\mathrm{O}$ (primarily silane based) had the most rapid initial drying, whereas $\mathrm{H}, \mathrm{K}, \mathrm{L}, \mathrm{N}$, and $\mathrm{O}$ (a variety of types) exhibit fastest initial drying for mortar specimens. Brick specimens $\mathrm{A}, \mathrm{B}, \mathrm{C}$, $D, F, H, K, L, M, N, O$, and $Q$ reached constant levels of less than $1 \%$ after 1000 hours in the drying chamber, whereas 
all mortar specimens reached this level within 250 hours, but these specimens were also rather small. As stated in the experiment's description, the drying experiment was carried out in a climate chamber with a temperature of $20^{\circ} \mathrm{C}$ and $85 \% \mathrm{RH}$. These conditions may not have been representative for real boundary conditions for a masonry wall, as it is also exposed to e.g. solar radiation and wind. However, for comparison purposes, these conditions were expected to give a correct picture of the influence of surface treatment on drying potential.

The simplified ranking system described in section 2.2.1 was introduced in order to try and evaluate the various results, despite some of the results being contradictory, the ranking system yields opportunity for evaluation of overall results. The ranking was performed as described in section 2.2.1, of the various hydrophobization agents based on the initial investigation is seen in Table 9.

Table 9: Ranking of the various hydrophobization treatments for brick and mortar altogether, and brick and mortar individually.

\begin{tabular}{|c|c|c|c|c|c|}
\hline \multicolumn{6}{|c|}{ Ranking by 3 categories } \\
\hline Brick and mortar & $\sum$ Score & Brick & ¿Score & Mortar & $\sum$ Score \\
\hline 0 & 297 & 0 & 314 & G & 116 \\
\hline $\mathrm{N}$ & 239 & $\mathrm{~N}$ & 268 & $\mathrm{E}$ & 90 \\
\hline 1 & 230 & 1 & 189 & M & 85 \\
\hline $\mathrm{M}$ & 213 & $\mathrm{~J}$ & 168 & $\mathrm{~L}$ & 82 \\
\hline $\mathrm{J}$ & 195 & M & 128 & $\mathrm{P}$ & 57 \\
\hline $\mathrm{E}$ & 186 & $E$ & 96 & $\mathrm{H}$ & 44 \\
\hline $\mathrm{P}$ & 132 & $\mathrm{P}$ & 75 & I & 41 \\
\hline G & 128 & A & 49 & K & 40 \\
\hline L & 81 & G & 12 & $\mathrm{~J}$ & 27 \\
\hline $\mathrm{K}$ & 25 & B & 10 & $\mathrm{Q}$ (reference) & 0 \\
\hline $\mathrm{H}$ & 17 & $\mathrm{~F}$ & 4 & 0 & -17 \\
\hline$Q$ (reference) & 0 & $\mathrm{Q}$ (reference) & 0 & B & -24 \\
\hline A & -9 & $\mathrm{~L}$ & -1 & D & -24 \\
\hline B & -14 & D & -15 & $\mathrm{~N}$ & -29 \\
\hline D & -39 & $\mathrm{~K}$ & -15 & C & -31 \\
\hline C & -50 & C & -19 & A & -58 \\
\hline $\mathrm{F}$ & -64 & $\mathrm{H}$ & -27 & $\mathrm{~F}$ & -68 \\
\hline
\end{tabular}

The water uptake experiment distinctly showed the reduction in initial water uptake for most hydrophobization agents, as expected, due to the purpose of the surface treatment. This was also illustrated in [20]. It is evident that hydrophobization treatments of silane rather than siloxane $(\mathrm{O}, \mathrm{N}, \mathrm{I}, \mathrm{J}$, and $\mathrm{M})$ seemed to perform better overall, and especially on bricks. However they seemed less efficient on the lime mortar. I and J performed better on the mortar, compared to $\mathrm{O}$ and $\mathrm{N}$, which may be explained by the creamy consistency and application method. On the mortar, agents G, E, M, L and P seemed the most efficient; these are hybrids, silane and nanotechnology based. 
Overall, it was seen that brick generally is more susceptible to hydrophobization treatment, and the effect is more pronounced in brick samples. The silane based agents seemed to perform better in the initial investigation, and agent $\mathrm{M}$ was represented in top-5 of all the ranking lists.

With regard to the study by Guizzardi et al.[21] stating that moisture transport occurred faster in bricks rather than mortar, the lesser efficiency observed in hydrophobization of the lime mortar may not be crucial for the overall effect of hydrophobization on a masonry construction. On the other hand, the study by Van Hees proved the opposite, why mortar joints may in fact be the weakest part of the masonry, emphasizing the need for hydrophobization efficiency of masonry in a holistic perspective. Many historic façades have been renovated since the 1940's; thus it can be expected that the external part of the joints in some cases has been replaced with a cementitious, siliceous mortar, and why the effect of hydrophobization on this type of mortar should be investigated. Based on the studies by Zhang et al. [10] and Slapø et. al, mortar with a high water content is recommended for façade renovations, as it reduces the water ingress in itself, and enhances the effect of a hydrophobization treatment.

The hydrophobization treatments examined did not seem to have a negative effect on the drying capability of specimens, nor the diffusion resistance, as also seen in the study by Engel et al. [22]The present study did not show the same results in regards to concentrations and drying, as different agents were used, and not only various concentrations of an active component. Previous studies found that water vapour permeability was reduced by application of hydrophobization [12,23], however that is not the case in the present study or in the work by Van Hees, who observed only a limited effect on the vapour permeability. Van Hees [24] and Couto et al. [23] did find the treatments to have a high impact on the drying capabilities, however that was not the case in the present study.

Similar to the study by Lubelli et al. [25], the nano-coating included in this study, namely $\mathrm{G}$ and $\mathrm{H}$, performed well on mortar specimens in regards to water uptake and drying, and the penetration depth here was found to be similarly small. In the present study, the performance of nano coatings on brick specimens in the, were however not of noteworthy character.

From the investigation of water migration through masonry, it was seen that the hydrophobization treatment had the largest effect on the external part of the masonry, and to a lesser extent through the wall. Hydrophobization combined with ordinary paint on the internal side, however, seemed to generate the lowest relative humidities and moisture 
content in internal measuring points. Thus the hydrophobization treatment on the masonry seemed to have the desired effect, despite the initial investigation showing less effect of hydrophobization on the lime mortar. The moisture migrations in walls with foam concrete and ACC seemed to be unaffected by the insulation type, however, the walls insulated with PUR with integrated capillary active channels showed the best results in the interface between insulation and masonry, regardless of the hydrophobization treatment. The internal surface treatments seemed to be influential on the results, as the cases with ordinary paint (1.3 and 2.3) exhibit lower relative humidities compared to cases with diffusion open paint. The results are similar to those found by Finken et al. [5], that the hydrophobization has a positive effect on the hygrothermal conditions of internally insulated masonry walls.

The 24 hour cycles implemented did not represent true nature, as the repeatability of the exact loads is highly unlikely. Despite this fact, the setup and the cycles represented realistic loads and gave results suitable for interpretation of WDR penetration of solid masonry, both with and without hydrophobization. It should be mentioned, that the rain loads hit only the top of each wall section, and water ingress through the lower masonry occurred due to runoff. As mentioned, the sensors were located in the middle of the wall section, and thus rather than a severe rain event, it may in fact have been of lesser severity at this location.

Future investigations could include the durability of each hydrophobization treatment, e.g. in masonry with a high salt content, or how various chemicals affect the effectiveness of hydrophobization. Furthermore, the durability in regards to climatic exposure in the form of UV-radiation, rain and erosion could be studied. In addition, the large scale experiment could have been equipped with sensors in the mortar joints as well, for determination of moisture migration in these.

\section{Conclusion}

The study concludes that a hydrophobization treatment had the desired effect of reduced rain water penetration on historic masonry, however this effect was more pronounced in the brick as compared to the lime mortar. For specimens of ceramic brick, silane based agents proved to have the best properties, however, for mortar a variety of active components were most efficient. Drying of treated specimens was not significantly influenced for brick; however the drying of lime mortar was slightly impeded by the hydrophobic treatment. Furthermore, the investigation showed that 
the vapour diffusion, through both brick and mortar, was not influenced by the hydrophobization treatments. The investigation of moisture migration through masonry showed a distinctive effect of hydrophobization, especially in the external part of the wall, indicating a potential for protection from frost damages and biological growths. The hydrophobization treatment in general also yielded lower relative humidities throughout the wall in most cases; however walls insulated with PUR with calcium silicate channels generally performed better in the critical interface, regardless of hydrophobization. The internal surface treatments also seemed to influence the results, and the two cases with ordinary paint show better results compared to their equivalents with diffusion open paint.

\section{Acknowledgements}

The presented work is a part of RIBuild project that has received funding from the European Union's Horizon 2020 research and innovation programme under grant agreement No 637268.

\section{References}

[1] H. Tommerup, S. Svendsen, Energy savings in Danish residential building stock, Energy Build. 38 (2006) 618626. doi:10.1016/j.enbuild.2005.08.017.

[2] T. Odgaard, S.P. Bjarløv, C. Rode, M. Vesterløkke, Building renovation with interior insulation on solid masonry walls in Denmark - A study of the building segment and possible solutions, Energy Procedia. 78 (2015) 830835. doi:10.1016/j.egypro.2015.11.003.

[3] E. Vereecken, L. Van Gelder, H. Janssen, S. Roels, Interior insulation for wall retrofitting - A probabilistic analysis of energy savings and hygrothermal risks, Energy Build. 89 (2015) 231-244. doi:10.1016/j.enbuild.2014.12.031.

[4] B. Blocken, J. Carmeliet, A review of wind-driven rain research in building science, J. Wind Eng. Ind. Aerodyn. 92 (2004) 1079-1130. doi:10.1016/j.jweia.2004.06.003.

[5] G.R. Finken, S.P. Bjarløv, R.H. Peuhkuri, Effect of façade impregnation on feasibility of capillary active thermal internal insulation for a historic dormitory - A hygrothermal simulation study, Constr. Build. Mater. 113 (2016) 
[6] E. Vereecken, S. Roels, Capillary active interior insulation: do the advantages really offset potential disadvantages?, Mater. Struct. 48 (2015) 3009-3021. doi:10.1617/s11527-014-0373-9.

[7] H.M. Künzel, Simultaneous Heat and Moisture Transport in Building Components - One- and two-dimensional

[10] J. Macmullen, Z. Zhang, E. Rirsch, H. Nath, N. Bennett, Brick and mortar treatment by cream emulsion for improved water repellence and thermal insulation, Energy Build. 43 (2011) 1560-1565. doi:10.1016/j.enbuild.2011.02.014.

[11] H. Mayer, Masonry Protection with Silanes, Siloxanes and Silicone Resins, Surf. Coatings Int. 81 (1998) 89-93.

[12] E. Charola, Water-Repellent Treatments for Building Stones, J. Preserv. Technol. Technol. 26 (1995) 10-17. http://www.jstor.org/stable/1504480.

[13] H.R. Trechsel, M.T. Bomberg, Moisture Control in Buildings: The Key Factor in Mold Prevention, 2nd ed., ASTM International, 1994. http://books.google.com/books?id=_pc6X3yvYsIC\&pgis=1.

[14] H. Boostani, S. Modirrousta, Review of Nanocoatings for Building Application, Procedia Eng. 145 (2016) 15411548. doi:10.1016/j.proeng.2016.04.194.

[15] H. Sandholdt, D. Dysted, Experimental and theoretical investigation of Interior insulations of solid brick walls with foam concrete and other silicate based materials, 2015. DTU Civil Engineering. 
[16] A. Nicolai, J. Grunewald, Delphin 5 User Manual and Program Reference, Program. (2006).

[17] Remmers, Technical data sheet - Funcosil FC, (n.d.) 1-3.

[18] D. Niels Hansen, Hvad kan du forvente, når DMI varsler skybrud?: DMI, (2015). https://www.dmi.dk/nyheder/arkiv/nyheder-2015/05/hvad-kan-du-forvente-naar-dmi-varsler-skybrud/ (accessed March 21, 2017).

[19] H. Kaaris, By og Byg Dokumentation 048, Klimasimulatorer. Teknisk dokumentation for accelereret ældning, perioden 1994-2002, 2003.

[20] T.K. Hansen, S.P. Bjarløv, R. Peuhkuri, Moisture transport properties of brick - comparison of exposed, impregnated and rendered brick, International RILEM Conference on Materials, Systems and Structures in Civil Engineering 2016 Segment on Moisture in Materials and Structures (2017) 351-360. http://orbit.dtu.dk/ws/files/128040737/Pages_from_Moisture_conf_proceedings_3.pdf.

[21] M. Guizzardi, D. Derome, R. Vonbank, J. Carmeliet, Hygrothermal behavior of a massive wall with interior insulation during wetting, Build. Environ. 89 (2015) 59-71. doi:10.1016/j.buildenv.2015.01.034.

[22] R.P.J. Van Hees, The performance of surface treatments for the conservation of historic brick masonry, in: Proc. CIB World Build. Congr. Gaevle, Sweden, 7-12 June 1998, 1998.

[23] F. Slap $\varnothing$, T. Kvande, N. Bakken, M. Haugen, J. Lohne, Masonry's Resistance to Driving Rain : Mortar Water, Buildings. 7 (2017) 70-86. doi:10.3390/buildings7030070.

[24] J. Engel, P. Heinze, R. Plagge, Adapting Hydrophobizing Impregnation Agents to the Object, Restoration of Buildings and Monuments 20 (2014) 1-8. doi:10.12900/RBM14.20.6-0029.

[25] S. Couto, T.D. Goncalves, J.M.G. Lopes, Drying of Red Ceramic Brick. The effect of five Silicone-based WaterRepellent Treatments., in: Hydrophobe VI. 6th International Conference on Water Repellent Treatment of Building Materials, 2011: pp. 81-92.

[26] B. Lubelli, R.P.J. Van Hees, Evaluation of the Effect of Nano-Coatings with Water Repellent Properties on the 
Absorption and Drying Behaviour of Brick, 136 (2011) 125-135. 